\title{
Identificação da viabilidade de sementes de orquídeas pelo teste de tetrazólio
}

\section{Orchid seeds viability identification by tetrazolium test}

\author{
Jackeline Schultz Soares ${ }^{1 *}$; Yara Brito Chaim Jardim Rosa ${ }^{2}$; Mariana Bento Tatara ${ }^{3}$; \\ José Carlos Sorgato ${ }^{4}$; Camila Soares Rosa Lemes ${ }^{4}$
}

\section{Resumo}

O conhecimento do potencial germinativo otimiza a prática de germinação in vitro de Orchidaceae. Este trabalho avaliou o tipo e a concentração de soluções de tetrazólio sobre o tempo de reação e a identificação de sementes viáveis de orquidáceas. Foram utilizadas sementes das espécies Brassavola tuberculata Hook, Cattleya labiata Lindley var Amoema, Cattleya intermedia e Dendrobium antenatum e de dois híbridos primários de Cattleya labiata autumnalis x Cattleya labiata Lindley var. Alba. As sementes $(0,01 \mathrm{~g})$ de cada espécie ou híbrido foram embebidas em $3 \mathrm{~mL}$ da solução aquosa ou da neutra de cloreto de 2,3,5 trifeniltetrazólio, nas concentrações de $0,0625 \%, 0,125 \%, 0,25 \%, 0,5 \%$ ou $1,0 \%$ e acondicionadas em ambiente desprovido de luz a $25 \pm 2{ }^{\circ} \mathrm{C}$, sendo avaliadas a cada 30 minutos para identificação do tempo necessário para a coloração dos embriões e posterior contagem do número de sementes viáveis por miligrama de sementes. Utilizou-se o delineamento experimental inteiramente casualizado, em esquema fatorial $6 \times 2 \times 5$ (seis genótipos de orquídeas, dois tipos de soluções tetrazólicas e cinco concentrações) com 3 repetições. Os genótipos estudados responderam diferentemente no que se refere ao número de sementes viáveis por miligrama de sementes e quanto ao tempo necessário para a coloração dos embriões, sendo que $C$. intermedia não respondeu ao teste. Independentemente do tipo de solução, as concentrações só interferiram no tempo de reação para um dos híbridos. Recomenda-se, portanto, a utilização de solução neutra de tetrazólio a $0,5 \%$ para identificação de sementes viáveis dos híbridos de Cattleya labiata autumnalis x Cattleya labiata var. Alba e a utilização de solução aquosa a $0,125 \%$ para as espécies Brassavola tuberculata, Cattleya labiata var Amoema e Dendrobium antenatum.

Palavras-chave: Floricultura, Orchidaceae, viabilidade de sementes

\begin{abstract}
The knowledge of germinal potential optimizes the practice of in vitro germination of Orchidaceae. This work evaluated of the type and concentrations of tetrazolium solutions on reaction time and on the identification of viable orchid seeds. Were used seeds of the species Brassavola tuberculata Hook, Cattleya labiata Lindley var Amoema, Cattleya intermedia and Dendrobium antenatum and of two primary hybrids of Cattleya labiata autumnalis x Cattleya labiata Lindley var. Alba. The seeds $(0.01 \mathrm{~g})$ of each species or hybrid were soaked in $3 \mathrm{~mL}$ of aqueous and neutral solutions of 2, 3, 5 triphenyltetrazolium chloride at $0.0625 \%, 0.125 \%, 0.25 \%, 0.5 \%$ and $1.0 \%$ concentrations and stored

\footnotetext{
${ }^{1}$ Discente do Curso de Doutorado do Programa de Pós-Graduação em Recursos Naturais, Universidade Estadual de Mato Grosso do Sul, UEMS, Dourados, MS. E-mail: jacke.schultz@gmail.com

${ }^{2}$ Prof ${ }^{\mathrm{a}}$, Faculdade de Ciências Agrárias, FCA, Universidade Federal da Grande Dourados, UFGD, Dourados, MS. E-mail: yararosa@ufgd.edu.br

3 Técnica de Laboratório da Faculdade de Ciências da Saúde, FCS, UFGD, Dourados, MS. E-mail: marianatatara@gmail.com

${ }^{4}$ Discentes do Curso de Doutorado do Programa de Pós-Graduação em Agronomia, UFGD, Dourados, MS. E-mail: jc_sorgato@ hotmail.com; camisrosa@yahoo.com.br

* Autor para correspondência
} 
in a light-free environment at $25 \pm 2{ }^{\circ} \mathrm{C}$, being evaluated every 30 minutes for identification of the time needed for embryos coloring and later counting of the number of viable seeds by milligram of seed. A completely randomized design was used, in a factorial scheme $6 \times 2 \times 5$ (six genotypes of orchids, two types of tetrazolium solutions and five concentrations) with 3 replications. The genotypes responded differently both for viable seeds by milligram of seed and for the time required for embryos coloring and $C$. intermedia not respond to the test. Irrespective of solution type, concentrations only interfered in reaction time for the hybrids. It is recommended, therefore, the use of neutral tetrazolium solution at $0.5 \%$ for indentification of viable seeds of hybrids of Cattleya labiata autumnalis x Cattleya labiata var. Alba and use of aqueous solution at $0.125 \%$ for Brassavola tuberculata, Cattleya labiata var Amoema and Dendrobium antenatum.

Key words: Flowering, Orchidaceae, seed viability test

\section{Introdução}

A maioria das espécies de orquídeas produz frutos com grande quantidade de sementes, as quais apresentam diferentes proporções de viabilidade, decorrentes do tipo de polinização e do armazenamento utilizado (BLOSSFELD, 1999).

Em vista disso, cultivadores mais experientes, após uma prévia observação ao microscópio, detectam a porcentagem aproximada de sementes com embrião, controlando assim a quantidade de sementes depositadas em cada frasco de cultivo, obtendo uma cultura homogênea em relação à quantidade de plântulas e minimizando custos decorrentes dos subcultivos. Entretanto, apenas a identificação do embrião nas sementes não é certeza da sua germinação, uma vez que as sementes de orquídeas perdem a viabilidade rapidamente (JORDÃO, 1990).

A avaliação da qualidade fisiológica das sementes é de extrema importância para o uso ou descarte de lotes de sementes, destinados à germinação ou armazenamento. Uma maneira rápida e de baixo custo para avaliar o potencial fisiológico das sementes é a aplicação do teste de tetrazólio que possibilita a avaliação da viabilidade para fins de semeadura (PINA-RODRIGUES; FIGLIOLIA; PEIXOTO, 2004). Esse teste apresenta como vantagens em relação ao teste de germinação in vitro, a rapidez e o fato de não ser afetado por microrganismos (FRANÇA NETO; KRZYZANOWSKI; COSTA, 1998).
$\mathrm{O}$ teste de tetrazólio reflete a atividade das enzimas desidrogenases, envolvidas no processo de respiração. Pela hidrogenação do 2,3,5 trifeniltetrazólio é produzida, nas células vivas, uma substância vermelha, estável e não difusível, o trifenil formazan. Isto torna possível distinguir as partes vivas, coloridas de vermelho, daquelas mortas que não colorem (OLIVEIRA; CARVALHO; DAVIDE, 2005).

Para Gaspar-Oliveira, Martins e Nakagawa (2009a), diversos fatores podem interferir na obtenção de resultados satisfatórios no teste de tetrazólio, principalmente aqueles relacionados à metodologia de execução como o preparo das sementes antes da exposição ao sal - por exemplo, a escarificação com $10 \%$ de hipoclorito de sódio e o uso de sacarose no pré-condicionamento (HOSOMI et al., 2011); a concentração da solução de tetrazólio - sendo as mais utilizadas $0,075 \%, 0,1 \%, 0,2 \%, 0,5 \%$ e $1,0 \%$ (MARCOS FILHO; CÍCERO; SILVA, 1987); o período e a temperatura de exposição à solução - geralmente entre 24 e 48 h, a $25^{\circ} \mathrm{C}$ (HOSOMI et al., 2011); e os critérios de interpretação utilizados - tais como embriões totalmente coloridos, embriões incolores e parcialmente corados (MARQUES JUNIOR et. al., 2012). Ainda, segundo Hosomi (2009), a concentração da solução do sal somada ao tempo de exposição das sementes ao teste é fundamental para a obtenção de resultados confiáveis.

Souza (1994) salienta que as variações entre os resultados obtidos, em diferentes laboratórios, para 
a viabilidade de sementes devem-se, em muitos casos, à alta acidez da solução de tetrazólio utilizada. Uma das alternativas para a obtenção de resultados confiáveis é a utilização de soluções aquosas de cloreto de tetrazólio, que não sejam ácidas.

Frequentemente, soluções de tetrazólio preparadas com água destilada são ácidas, o que pode colorir de forma inadequada os embriões, causando interpretações errôneas do estado de viabilidade das sementes. Este problema pode ser evitado mediante a utilização de uma solução tampão de fosfato no preparo do sal, que assegura a manutenção do $\mathrm{pH}$ dentro da faixa aceitável, resultando numa solução neutra, com o pH ideal situando-se entre 6,0 e 8,0 (SOUZA, 1994).

As informações gerais para a realização do teste de tetrazólio, para um grande número de espécies, estão indicadas nas Regras Para Análise de Sementes (BRASIL, 2009) e têm sido aprimoradas nos últimos anos. Entretanto a sua utilização para Orchidaceae ainda necessita de informações que otimizem seus resultados uma vez que a metodologia para a sua realização ainda não foi completamente estabelecida.

Assim, objetivou-se com este trabalho avaliar dois tipos de solução de tetrazólio, em diferentes concentrações, sobre o tempo de reação e a identificação de sementes viáveis de seis genótipos de orquídeas.

\section{Material e Métodos}

O experimento foi conduzido no Laboratório de Cultivo in vitro da Faculdade de Ciências Agrárias FCA da Universidade Federal da Grande Dourados (UFGD - Dourados, MS).

Como material de estudo foram utilizadas sementes, recém colhidas, dos frutos de Brassavola tuberculata Hook (Bt) obtidos por polinização natural, provenientes de uma reserva legal do município de Dourados - MS, localizada nas coordenadas $22^{\circ} 24^{\prime} \mathrm{S}$ e $54^{\circ} 46^{\prime} \mathrm{W}$, com altitude média de $327 \mathrm{~m}$. As médias anuais de temperatura do ar máxima e mínima são de 24 e $20{ }^{\circ} \mathrm{C}$, respectivamente, com precipitação total anual entre 1250 e $1500 \mathrm{~mm}$. A luminosidade média local, sob dossel, é de $280 \mu \mathrm{mol} \mathrm{m} \mathrm{m}^{-2} \mathrm{~s}^{-1}$.

Foram utilizadas, ainda, sementes recém colhidas, oriundas de frutos produzidos mediante autopolinização manual das espécies Cattleya labiata Lindley var Amoema (Cl), Cattleya intermedia (Ci) e Dendrobium antenatum (Da). Também foram utilizadas sementes dos frutos de dois híbridos primários de Cattleya labiata autumnalis x Cattleya labiata Lindley var. Alba. Foi denominado como hibrido 1 (H1) aquele que teve como receptora a Cattleya labiata autumnalis e como doadora a Cattleya labiata Lindley var. Alba e como híbrido 2 (H2) o inverso. Os genótipos que deram origem a essas sementes estavam localizados em viveiros providos de tela de sombreamento de

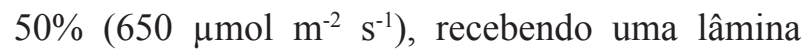
d'água semanal equivalente a $2 \mathrm{~mm}$. As temperaturas médias anuais do local variaram de 22 a $24{ }^{\circ} \mathrm{C}$.

A solução aquosa (SA) de tetrazólio a $1 \%$ foi obtida por meio da dissolução de $10 \mathrm{~g}$ de cloreto de 2,3,5 trifeniltetrazólio P.A. (Tz) em 1 litro de água destilada ( $\mathrm{SA}=\mathrm{Tz}+$ água destilada). Já a solução neutra (SN) a 1\% (SOUZA, 1994), foi obtida por meio da dissolução de $10,73 \mathrm{~g}$ de $\mathrm{Na}_{2} \mathrm{HPO}_{4} \cdot 7 \mathrm{H}_{2} \mathrm{O}$ em $600 \mathrm{~mL}$ de água e de 3,63 g de $\mathrm{K}_{2} \mathrm{PO}_{4}$ em 400 $\mathrm{mL}$ de água totalizando 1 litro de solução. A esta solução foram acrescidos $10 \mathrm{~g}$ de cloreto de 2,3,5 trifeniltetrazólio P.A $\left(\mathrm{SN}=\mathrm{Tz}+\mathrm{Na}_{2} \mathrm{HPO}_{4} \cdot 7 \mathrm{H}_{2} \mathrm{O}+\right.$ $\mathrm{K}_{2} \mathrm{PO}_{4}+$ água destilada). As duas soluções foram diluídas para concentrações de $0,5 \%, 0,25 \%$, $0,125 \%$ e $0,0625 \%$ obtendo-se soluções com $\mathrm{pH}$ igual a $\mathrm{SN}=6,5$ e $\mathrm{SA}=5,7$.

As cápsulas foram abertas com estilete e as sementes de cada espécie ou híbrido estudado foram separadas em porções de $0,01 \mathrm{~g}$ cada. As porções, sem prévia embebição, foram colocadas em tubos de ensaio e cada uma delas recebeu $3 \mathrm{~mL}$ de uma das concentrações das soluções de tetrazólio estudadas. 
As suspensões de sementes foram acondicionadas em ambiente desprovido de luz a $25 \pm 2{ }^{\circ} \mathrm{C}$, sendo avaliadas a cada 30 minutos, durante 140 horas. Após a coloração das sementes, as suspensões de tetrazólio foram acrescidas de $7 \mathrm{~mL}$ de água destilada para facilitar a contagem. Na sequência, cada mililitro da suspensão foi transferido para câmara de Peters, para contagem e identificação de sementes viáveis, com o auxílio de microscópio estereoscópico.

Foi contabilizado o número total de sementes nas $10 \mathrm{mg}$ e, desse total, foram consideradas como viáveis apenas as sementes com embriões totalmente coloridos de carmin, enquanto que as sementes com embriões incolores, parcialmente corados ou aquelas desprovidas de embrião foram consideradas inviáveis. Posteriormente foi calculado o número de sementes viáveis, por miligrama de sementes de cada genótipo estudado.
$\mathrm{O}$ experimento foi analisado no delineamento experimental inteiramente casualizado, em esquema fatorial $6 \times 2 \times 5$ (seis genótipos de orquídeas, dois tipos de soluções tetrazólicas e cinco concentrações) com 3 repetições de um tubo de ensaio cada. O tempo necessário para coloração do teste e o número de sementes viáveis por miligrama de sementes foram submetidos à análise de variância com o uso do aplicativo computacional SISVAR 5.3 (FERREIRA, 2010) e, quando significativas, às médias foram ajustadas curvas de regressão.

\section{Resultados e Discussão}

O número de sementes viáveis por miligrama de sementes e o tempo para coloração dos embriões dos genótipos foram analisados estatisticamente $\mathrm{e}$ sua média geral, o resumo das análises de variância, bem como a significância dos fatores estudados são apresentados na Tabela 1 .

Tabela 1. Resumo das análises de variância do número de sementes viáveis por miligrama de sementes $\left(\mathrm{NSV} \mathrm{mg}^{-1}\right) \mathrm{e}$ do tempo de coloração dos embriões (TCE) dos genótipos de orquídeas estudados. Dourados, UFGD, 2010.

\begin{tabular}{lccc}
\hline & & \multicolumn{2}{c}{ Quadrados médios } \\
\cline { 3 - 4 } F.V. & GL & NSV mg & TCE \\
\hline Solução (S) & 1 & $34595,22^{* *}$ & $1700,16^{* *}$ \\
Concentração (C) & 4 & $24330,67^{* *}$ & $12,05^{\text {ns }}$ \\
Genótipo (A) & 4 & $2976903,89^{* *}$ & $22362,12^{* *}$ \\
S x C & 4 & $10343,34^{* *}$ & $20,49^{\text {ns }}$ \\
S x A & 4 & $8336,42^{* *}$ & $1970,46^{* *}$ \\
C x A & 16 & $10543,82^{* *}$ & $101,98^{* *}$ \\
S x C x A & 16 & $10500,46^{* *}$ & $29,88^{* *}$ \\
Erro & 100 & 1276,08 & 13,05 \\
Cv(\%) & & 14,88 & 12,48 \\
\hline Média geral & & 240,12 sementes & 28,95 horas \\
\hline
\end{tabular}

** significativo, a $1 \%$ de probabilidade, pelo teste $\mathrm{F}$

* significativo, a 5\% de probabilidade, pelo teste $\mathrm{F}$

${ }^{\text {ns }}$ não significativo.

Fonte: Elaboração dos autores.

Número de sementes viáveis por miligrama de sementes (NSV)

Houve efeito isolado e conjunto $(\mathrm{p}<0,01)$ de todos os fatores estudados sobre o número de sementes viáveis. Em relação à utilização das soluções aquosa ou neutra, a solução neutra foi mais eficaz na identificação de sementes viáveis, apresentando, em média, 255,30 sementes, valor este estatisticamente 
superior $(p<0,01)$ às 224,93 identificadas pela solução aquosa. Independente do tipo de solução, os menores números de sementes viáveis foram observados com a utilização de soluções a $1 \%$. Essas soluções identificaram em média 192,50 sementes enquanto que as demais identificaram, em média, 252,02 sementes. Resultados semelhantes foram observados por Gaspar-Oliveira, Martins e Nakagawa (2009b) com sementes de outras famílias botânicas, como Euphorbiaceae, Fabaceae, Cucurbitaceae e Solanaceae, para as quais soluções tetrazólicas menos concentradas que as prescritas nas Regras para Análise de Sementes (BRASIL, 2009) têm possibilitado melhores resultados.

Os resultados relativos ao menor número de sementes viáveis identificadas pelas soluções a $1 \%$ podem ser decorrentes da morfologia das sementes das orquídeas. A embebição de sementes é um processo no qual a entrada da água ocorre passivamente devido à diferença de potencial hídrico entre a semente e o meio (do potencial hídrico mais alto para o mais baixo). Em orquídeas esta embebição pode ser difícil, uma vez que a superfície das sementes é geralmente provida de ornamentação, o que facilita sua dispersão pelo vento e água, favorecendo a flutuabilidade e dificultando a penetração da água (ARDITTI, 1992; PRIDGEON et al., 1999). Concentrações mais elevadas do sal tetrazólico estudadas somadas ao tamanho diminuto da semente e suas características morfológicas podem proporcionar resposta reversa ao teste, ou seja, ao invés da solução tetrazólica penetrar nos tecidos da semente, a semente perde água para a solução, dificultando a identificação da viabilidade.

Este estudo também constatou que existe diferença entre o número de sementes viáveis por miligrama de sementes em função dos genótipos utilizados. Os maiores números foram observados em Bt (747,73 a) seguido do H2 (344,26 b), H1
(85,33 c) e este da $\mathrm{Cl}(15,60 \mathrm{~d})$ estatisticamente igual ao $\mathrm{Da}(7,66 \mathrm{~d})$, enquanto para Ci não foram registradas sementes viáveis.

Vujanovic et al. (2000) também verificaram ausência de um padrão de resposta ao teste de tetrazólio em três espécies de orquídeas terrícolas, com utilização de soluções a 1 e $2 \%$ do sal. Das espécies estudadas pelos autores apenas uma reagiu à solução, apresentando coloração característica do teste. A ausência do padrão de coloração característica desse teste, independentemente da concentração da solução utilizada, é atribuída, por Pritchard (1985) e Vierheiling et al. (1998), a diferentes reações do tecido das sementes na presença de corantes específicos, enquanto van Waes e Debergh (1986) a relaciona com a variação da permeabilidade do tegumento das sementes.

Além da especificidade de cada híbrido ou espécie, o número de sementes viáveis por miligrama de sementes também é afetado por fatores abióticos tais como a luminosidade do local de cultivo. Rosa et al. (2011) observaram que em plantas cultivadas sob luminosidade de $237 \mu \mathrm{mol} \mathrm{m} \mathrm{m}^{-2} \mathrm{~s}^{-1}$ o número de sementes viáveis de Dendrobium nobile Lindl. foi $56 \%$ superior àquele obtido em frutos que foram formados e mantidos sob condição de luminosidade entre 154 e $104 \mu \mathrm{mol} \mathrm{m}^{-2} \mathrm{~s}^{-1}$. Este fator também deve ser levado em consideração, uma vez que as plantas que produziram as sementes não foram cultivadas no mesmo local.

Os efeitos conjuntos $(\mathrm{p}<0,01)$ dos três fatores estudados sobre o número de sementes viáveis são apresentados na Figura 1. Observou-se comportamento diferenciado entre as espécies e os híbridos estudados em relação aos tipos de solução de tetrazólio. As espécies apresentaram maior número de sementes viáveis (NSV) indentificado em solução aquosa (Figura 1 A e D) enquanto que nos híbridos o maior número de sementes viáveis foi identificado na solução neutra (Figura 1 B e C). 
Figura 1. Número de sementes viáveis por miligrama de sementes (NSV mg $\left.{ }^{-1}\right)$ dos genótipos de orquídeas em função do tipo (solução aquosa - SA e solução neutra - SN) e das concentrações das soluções de trifeniltetrazólio. (A) Brassavola tuberculata (Bt); (B) Cattleya labiata autumnalis x Cattleya labiata var. Alba (H1); (C) Cattleya labiata var. Alba x Cattleya labiata autumnalis (H2); (D) Dendrobium antenatum (Da) e Cattleya labiata (Cl). Dourados-MS, UFGD, 2010.
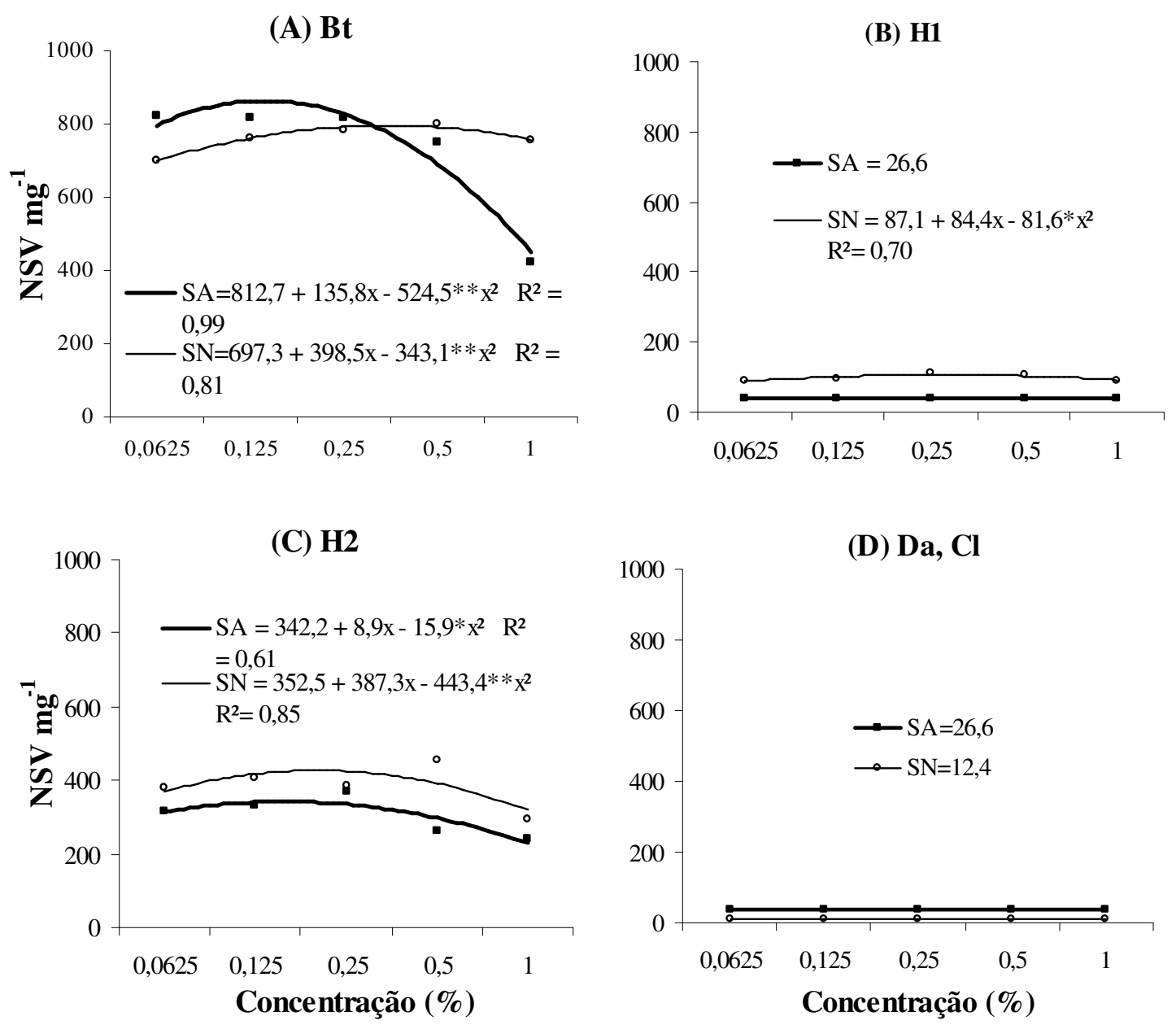

Fonte: Elaboração dos autores.

Para Bt o maior NSV (822) foi obtido na concentração estimada de $0,13 \%$ da solução aquosa, enquanto que na solução neutra obtevese a identificação de 813 sementes viáveis na concentração $\quad 0,60 \%$ (Figura $1 \mathrm{~A}$ ). Os maiores valores calculados de NSV de $\mathrm{H} 2$ foram observados na solução neutra em concentração $0,44 \%$ (437 sementes) enquanto que a solução aquosa identificou 343 sementes com a utilização da concentração $0,28 \%$.

$\mathrm{Na}$ solução aquosa, em H1, Da e $\mathrm{Cl}$ não foram observados efeitos significativos sobre o número de sementes viáveis apresentando média de 26,6 independentemente da concentração utilizada (Figura 1 B e D). Já na solução neutra H1 apresentou comportamento significativo quadrático com valor máximo calculado (109 sementes) na concentração $0,52 \%$ (Figura $1 \mathrm{~B}$ ), enquanto $\mathrm{Da}$ e $\mathrm{Cl}$ não foram influenciados significativamente $(p>0,05)$ apresentando média de 12,4 sementes coradas independentemente da concentração estudada (Figura 1 D). 
Embora Souza (1994) atribua maior eficiência e confiabilidade do teste tetrazólio ao $\mathrm{pH}$ da solução utilizada, que deve situar-se entre 6,0 e 8,0 para que a coloração dos embriões não ocorra de forma inadequada, causando interpretações errôneas do estado de viabilidade das sementes, este estudo aponta para uma especificidade do material vegetal estudado, uma vez que os dois híbridos apresentaram maior número de sementes viáveis em solução neutra, enquanto que as espécies apresentaram na aquosa.

Tempo de coloração dos embriões das sementes (TCE)

Houve efeito isolado $(\mathrm{p}<0,01)$ do tipo de solução e dos genótipos estudados sobre o tempo de coloração dos embriões. A solução neutra demorou em média 25,58 horas para colorir os embriões, enquanto que a aquosa demorou 32,32 horas. As concentrações da solução tetrazólica não apresentaram diferenças estatísticas $(\mathrm{p}>0,05)$ sobre esta variável e demoraram em média 28,95 horas para colorir os embriões. Os menores tempos de coloração foram observados em Bt (9,2 horas) seguido da Da (16,6 horas), H2 (19,7 horas), $\mathrm{Cl}$ (22,2 horas) e H1 (77,0 horas) todos estatisticamente diferentes entre si $(\mathrm{p}<0,01)$.

$\mathrm{O}$ genótipo $\mathrm{Ci}$ não apresentou coloração até 140 horas após a aplicação do teste, o que pode ter acontecido pela não utilização de précondicionamento, já que Hosomi et al. (2011) relataram a melhoria da coloração e diferenciação de sementes vivas e mortas após o pré-condicionamento de sementes de Cattleya walkeriana e C. leopoldii em solução de sacarose.

Efeitos conjuntos dos fatores estudados $(\mathrm{p}<0,01)$ foram observados em todas as combinações testadas, exceto para solução $x$ concentração $(p>0,05)$ (Tabela 1). Ao se analisar o efeito das soluções, das concentrações e dos genótipos de orquídeas estudados, observou-se efeito significativo $(p<0,01)$ apenas para o H1 (Figura 2 B). Observou-se que a solução aquosa diminuiu o tempo de coloração para as espécies $\mathrm{Bt}$ e $\mathrm{Cl}$ (Figura $2 \mathrm{~A}$ e E), sendo estatisticamente igual à solução neutra para a Da (Figura 2 D). Já para os híbridos, o menor tempo de coloração dos embriões foi observado na solução neutra (Figura $2 \mathrm{~B}$ e C).

Os embriões de Bt demoraram, em média, 8,2 horas para colorir em solução aquosa e 10,2 horas em solução neutra (Figura $2 \mathrm{~A}$ ). Já o tempo de reação do teste em $\mathrm{Cl}$ foi de 21,3 horas em solução aquosa e de 23,1 horas na neutra (Figura 2 E). Em solução aquosa H2 demorou 20,6 horas para reagir e em solução neutra 18,8 horas (Figura 2 C). Em ambas as soluções, Da demonstrou o mesmo comportamento, levando aproximadamente 16,5h para colorir os embriões (Figura $2 \mathrm{D})$.

Em ambas as soluções, H1 apresentou comportamento quadrático (Figura 2 B). Para a solução neutra o maior tempo de reação calculado foi de 74,61 horas, na concentração $0,99 \%$ e para a aquosa 98,83 horas na concentração $0,77 \%$. Estes resultados indicam que concentrações maiores ou menores que estas implicarão em um menor tempo de coloração dos embriões das sementes desse genótipo.

Os resultados encontrados neste estudo se contrapõem aos relatados por Hosomi et al. (2011), uma vez que apenas o tipo de solução e não as suas concentrações interferiram no tempo de coloração dos embriões de quatro dos genótipos de orquídeas estudadas (Figura 2 A, C, E e D) sendo que apenas para o híbrido H1 houve efeito das concentrações no tempo da reação do teste de tetrazólio (Figura 2 B). Mesmo para H1 (Cattleya labiata autumnalis $\mathrm{x}$ Cattleya labiata var. Alba), os resultados divergem dos autores supracitados, uma vez que os menores tempo de reação $(43,2 \mathrm{~h}$ - SN e 89,7 h - SA) foram observados na concentração de $0,0625 \%$, enquanto que os autores recomendam a utilização de concentrações da solução de tetrazólio superiores a 0,25\% para sementes do gênero Cattleya. 
Figura 2. Tempo de coloração dos embriões (TCE) dos genótipos de orquídeas em função do tipo (solução aquosa - SA e solução neutra - SN) e das concentrações das soluções de trifeniltetrazólio. (A) Brassavola tuberculata (Bt); (B) Cattleya labiata autumnalis x Cattleya labiata var. Alba (H1); (C) Cattleya labiata var. Alba x Cattleya labiata autumnalis (H2); (D) Dendrobium antenatum (Da); (E) Cattleya labiata (Cl). Dourados-MS, UFGD, 2010.
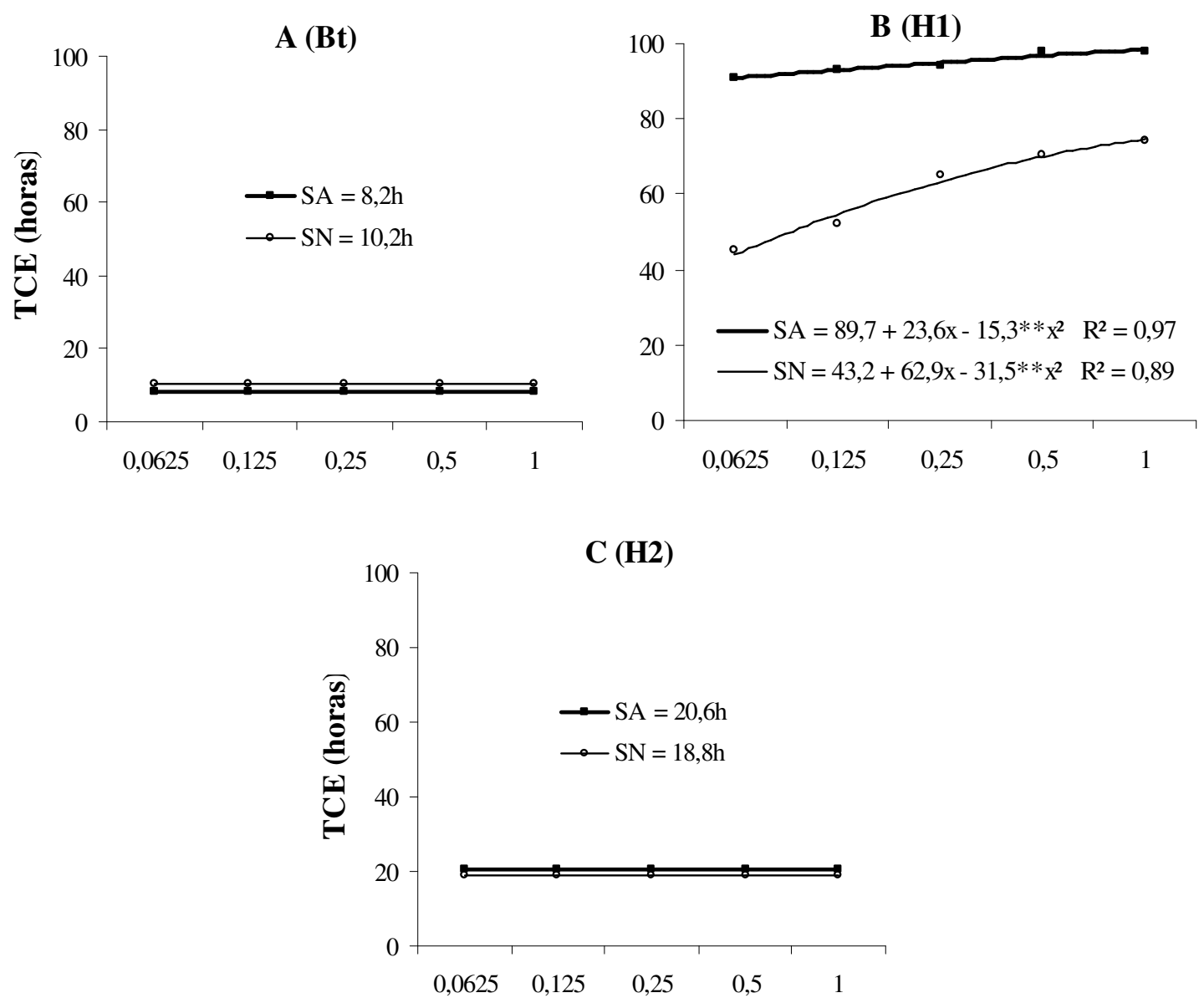

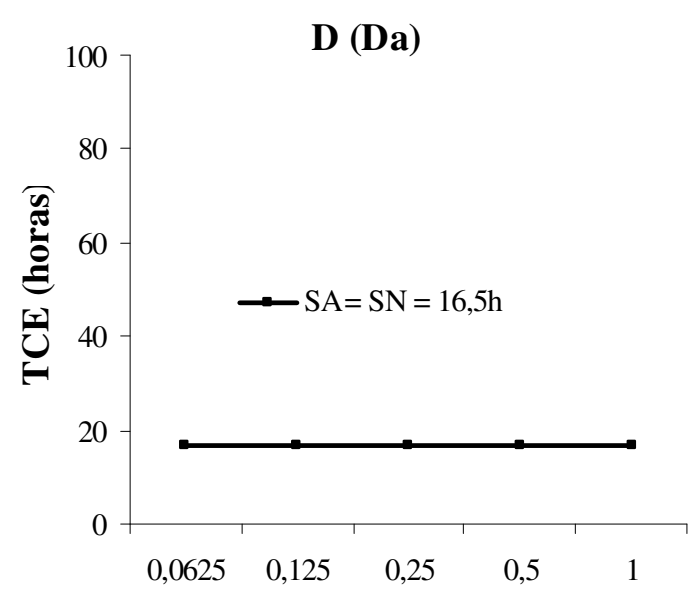

Concentração $(\%)$

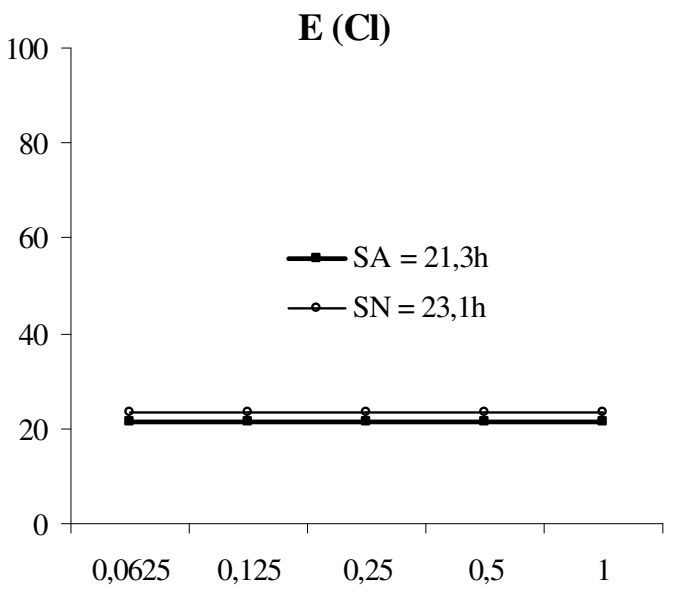

Concentração (\%)

Fonte: Elaboração dos autores. 
Considerando os resultados obtidos nesse trabalho e os relatos de Hosomi et al (2011), pode-se inferir que cada genótipo responde diferenciadamente ao teste de tetrazólio. Essas diferenças podem ser atribuídas não apenas ao tipo de solução e sua concentração, mas também às condições nas quais os frutos foram produzidos, seu estágio de maturação e aos processos utilizados na pós-coleta dos mesmos (MARQUES JUNIOR et al., 2012).

\section{Conclusão}

O tipo de solução de tetrazólio interfere no tempo de reação do teste e na identificação de sementes viáveis dos genótipos de orquídeas. Recomenda-se a utilização de solução neutra de tetrazólio de $0,5 \%$, para identificação de sementes viáveis dos híbridos de Cattleya labiata autumnalis x Cattleya labiata Lindley var. Alba e a utilização de solução aquosa a 0,125\% para as espécies Brassavola tuberculata, Cattleya labiata var Amoema e Dendrobium antenatum.

\section{Referências}

ARDITTI, J. Fundamentals of orchid biology. Toronto: John Wiley \& Sons, 1992. 691 p.

BLOSSFELD, A. Orquidologia, orquidofilia $e$ orquicultura. Jaboticabal: FUNESP, 1999. 89 p.

BRASIL. Ministério da Agricultura, Pecuária e Abastecimento. Regras para análise de sementes. Ministério da Agricultura, Pecuária e Abastecimento. Secretaria de Defesa Agropecuária. Brasília, DF: Mapa/ ACS, 2009. 395 p.

FERREIRA, D. F. SISVAR - Sistema de análise de variância. Versão 5.3. Lavras, MG: UFLA, 2010.

FRANÇA NETO, J. B.; KRZYZANOWSKI, F. C.; COSTA, N. P. O teste de tetrazólio em sementes de soja. Londrina: EMBRAPA-CNPSo, 1998. 72 p. (EmbrapaCNPSo. Documento, 116).

GASPAR-OLIVEIRA, C. M.; MARTINS, C. C.; NAKAGAWA, J. Concentração da solução de tetrazólio e período de coloração do teste para sementes de mamoneira. Revista Brasileira de Sementes, Londrina, v. 31, n. 3, p. 38-47, 2009b.

Método de preparo das sementes de mamoneira (Ricinus communis L.) para o teste de tetrazólio. Revista Brasileira de Sementes, Londrina, v. 31, n. 1, p. 160-167, 2009a.

HOSOMI, S. T. Germinação, viabilidade $e$ armazenamento de Cattleya (Orchidaceae). 2009. Dissertação. (Mestrado em Agronomia) - Universidade do Oeste Paulista, Presidente Prudente.

HOSOMI, S. T.; CUSTÓDIO, C. C.; SEATON, P. T.; MARKS, T. R.; MACHADO-NETO, N. B. Improved assement of viability and germination of Cattleya (Orchidaceae) seeds following storage. In vitro Cellular \& Developmental Biology - Plant, Wallingford, v. 48, n. 1, p. 127-136, 2011.

JORDÃO, L. R. Seleção de sementes viáveis de orquídeas pela separação por densidade. Boletim $C A O B$, São José do Rio Preto, v. 2, n. 4, p. 39-43, 1990.

MARQUES JUNIOR, G. A.; ROSA, Y. B. C. J.; SOARES, J. S.; ROSA, D. B. C. J.; MACEDO, M. C.; CEZAR, A. M. A. Germinação de Brassavola tuberculata Hook em função do período de armazenamento, do tempo de cultivo e de tratamento pré-germinativo. 2012. Monografia (Trabalho de Conclusão de Curso de Graduação em Agronomia) - Universidade Federal da Grande Dourados, Dourados.

MARCOS FILHO, J.; CÍCERO, S. M.; SILVA, W. R. Avaliação da qualidade das sementes. Piracicaba: FEALQ, 1987. $230 \mathrm{p}$.

OLIVEIRA, L. M.; CARVALHO, M. L. M.; DAVIDE, A. C. Teste de tetrazólio para avaliação de sementes de Peltophorum dubium (Sprengel) Taubert leguminosae caesalpinioideae. Cerne, Lavras, v. 11, n. 2, p. 159-166, 2005 .

PINA-RODRIGUES, F. C.; FIGLIOLIA, M. B.; PEIXOTO, M. C. Teste de qualidade. In: FERREIRA, A. G.; BORGHETTI, F. (Org.). Germinação: do básico ao aplicado. Porto Alegre: Artmed, 2004. p. 283-297.

PRIDGEON, A. M.; CRIBB, P. J.; CHASE, M. W.; RASMUSSEN, F. N. (Ed.). Genera Orchidacearum. General introduction, Apostasioideae, Cypripedioideae. Oxford: Oxford University; 1999. 64 p.

PRITCHARD, H. W. Determination of orchid seed viability using fluorescein diacetate. Plant, Cell and Environment, Malden, v. 8, n. 8, p. 727-30, 1985. 
ROSA, Y. B. C. J.; RAMOS, F. Z.; SOUZA, R. G.; ROSA JUNIOR, E. J.; LEMES, C. S. R.; ROSA, D.

B. C. J. Luminosidade na frutificação e germinação de Dendrobium nobile Lindl. In: ENCONTRO SOBRE ORQUÍDEAS NATIVAS E ADAPTADAS AO CERRADO BRASILEIRO, 1., 2011, Chapadão do Sul. Anais... Chapadão do Sul: UFMS, 2011. p. 1-4.

SOUZA, F. H. D. Preparo de soluções neutras de tetrazólio. Campo Grande: EMBRAPA Gado de Corte, 1994. 2 p. (COT, n. 51).

VAN WAES, J. M.; DEBERGH, P. C. Adaptation of the tetrazolium method for testing the seed viability, and scanning electron microscopy study of some Western
European orchids. Physiologia Plantarum, Malden, v. 66, n. 3, p. 435-42, 1986.

VIERHEILING, H.; COUGHLAN, A. P.; WYSS, U.; PICHÉ, Y. Ink and vinegar, a simple staining technique for arbuscular-mycorrhizal fungi. Applied and Environmental Microbiology, Washington, v. 64, n. 64, p. 5004-5007, 1998.

VUJANOVIC, V.; ST-ARNAUD, M.; BARABÉ, D.; THIBEAULT, G. Viability testing of orchid seed and the promotion of colouration and germination. Annals of Botany, Oxford, v. 86, n. 1, p. 79-86, 2000. 